\title{
Monitoring Training Intensity; Using a Tri-Phasic Model
}

\author{
Emma Swanwick*1, David Pyne ${ }^{2,3}$ and Martyn Matthews ${ }^{1}$ \\ ${ }^{1}$ School of Health Sciences, University of Salford, Frederick Road, Salford M6 6PU, UK \\ ${ }^{2}$ Research Institute for Sport and Exercise, Faculty of Health,University of Canberra, Canberra, ACT 2601, Australia \\ ${ }^{3}$ Discipline of Physiology, Australian Institute of Sport, Canberra, ACT, Australia
}

Received: June 04, 2018; Published: June 21, 2018

*Corresponding author: Emma Swanwick, School of Health Sciences, University of Salford, Frederick Road, Salford M6 6PU, UK. Email: ek.swanwick@ gmail.com

Abstract

Introduction: Different training models can produce the same outcome in competition. As the magnitude of change is dependent on the characteristics of the training programs, the duration of the intervention, and the gender, it is important to identify the training stimulus and how that relates to performance. The aim was to investigate the utility of a new model to describe training adaptions and outcomes.

Methods: 12 Swimming Australia Scholarship holders were followed over a 6-week initial training period. A range of sub maximal and maximal swims were used to assess their training state in week 0 week 3 and week 7 . We used a novel tri-phasic model to monitor and assess athlete conditioning.

Results: Aerobic contribution increase between test 1 and 3 was $8.25 \%( \pm 19.74 \%$;). Glycolytic metabolism showed a reduction in contribution of $-20.40 \%( \pm 10.82 \%)$ that was significant $(P=0.04)$. Anaerobically, there was an overall gain of $12.15 \%( \pm 11.70 \%$; $P=0.01)$ Findings. We demonstrated how the use of a new model of metabolic capability may help to explain physiological changes made by the athlete in response to the coaches intended outcome. In particular, we observed that Malate Aspartate (MAS) has a far greater role to play in retaining the equilibrium within skeletal muscle that allows higher intensity of aerobic exercise to continue in less aerobically friendly conditions.

\section{Introduction}

Performance at major championships requires good rates of improvement by the swimmer both during the year leading up to the meet, and during the competition itself [1]. An analysis of medal winners' times in both semi-finals and finals reveals that medalling requires a further improvement between semi and final also. To identify what the swimmer needs, and why it is needed, coaches seek to monitor training performance by a number of methods (heart rate, swimming speed, stroke rate, lactate). When, what, and duration of specific training, are also important elements of how the training program is put together. Measurement of training indices, however, even when used with multiple regression techniques, still do not appear to produce good markers of performance $[2,3]$. Different training models can produce the same outcome in competition [4] and, if a positive effect is to be maintained, the specificity of training requirements of international athletes needs to be retained in all training sessions at least $70 \%$ of the time [5]. As the magnitude of change is dependent on the characteristics of the training programs, the duration of the intervention, and the gender, [6] it is important to identify what stimulus is created by the training and how that relates to performance.
Physiological monitoring showed little relationship between the use of blood lactate testing and competition performance, [7] although monitoring in the final 4 weeks before a major competition could improve resilience of the training observation in relation to performance [8]. These changes, however, need to be relatively large $[2,9]$. Some researchers have suggested that training pace is a good marker of training intensity, [10] although later observers found that critical velocity was no different in the first and last week of a 14-week training program [11]. Swimmers appear to adhere closely to all aspects of training load, except intensity [12], which is not helped if coaches do not comply with scientific direction as the communication between the sport scientist and the coach is not forthcoming [13]. Wallace et al. [14] suggested that there were few practical methods available to evaluate training load during swimming, and showed that use of RPE heart-rate based methods were not consistent, and were generally a poor estimate of training load. Further, the training load identified by the coach and swimmer were not in agreement. Estimations of maximal heart rate also appear to be an imprecise guide to training pace in cycling and running, [15] however cardiac drift changes the heart rate power 
relationship significantly [16]. Although heart rate variability has been used in moderate fitness situations with some success [17], these authors also found it was very difficult to draw conclusions from this method in elite athletes [18].

Prescribing the intensity of training is somewhat problematic.13 Swim training is conducted using interval methods, which makes the attainment of steady state more difficult than in many other sports, and the use of lactate alone is seen as less than accurate [19]. The 3-way split of energy systems (aerobic, anaerobic and CPr-ATP) has been used by many authors and described in relation to athletic events [20]. We have previously described a need to view the function of the energy system split into 4 components rather than 3 [21]. Using this as the basis for generating a model of assessment, it is possible to use the maximum lactate from an effort and predict at what level of blood lactate MVO2 occurred. We would use this to define the point from which anaerobic capacity could be defined. Additionally, using the change in blood glucose, we proposed that it could be used to identify the amount of work that was met by aerobic glycolytic mechanisms. From the combination of these two, we could then finalize the total aerobic contribution within a maximal effort. This model has been tested rigorously and found to be reliable [22].

The aim of this study was to demonstrate the use of the triphasic model to monitor and assess athlete conditioning over a 6-week period and evaluate the utility of the new model to describe training adaptions and outcomes.

\section{Methods}

12 male members of the Australian Swimming Scholarship Holders volunteered to participate in this study. Participants (age
$19.70+0.95$, Mass $79.93+5.26$ ). The swimmers had returned from a 3-week vacation and the experiment was carried out after they had completed 1 week of basic, mixed stroke, training. For all subjects, training consisted of a mixture of low, moderate and maximal intensity aerobic work, short sprints and pool-based stroke specific drills and exercises. Weekly swimming training volume averaged $54 \pm 19 \mathrm{~km} /$ week-1 over the six weeks. All swimmers also carried out land-based training between three and five times per week consisting of resistance training circuits, strength training and flexibility work. To monitor changes during the 6 week training phase, the model outlined above was used to calculate the relative percentage contribution of the energy pathways by individuals to the work load during specific testing in week 1, week 4 and week 7. The model for the calculation of the three components: aerobic; glycolytic; anaerobic is as follows:

Lactate was calculated as:

Lactate at MVO2 “ $a$ " $=(($ max lactate $/((0.4571 * \max$ lactate $)+3.3524)) * 100)-100)$

Aerobic glycolysis was calculated as:

Glyc $\max " g "=100-((\max$ glucose / resting glucose $)) * 100$

Aerobic contribution therefore equalled:

$$
\text { Aerobic } \max =(100-(a+g))
$$

Where the total $=100 \%$.

The results of the above calculations were used to produce charts of individual and group responses to training as shown in Figure 1. The AIS research ethics board approved this study. All participants provided both verbal and written confirmation of their consent to participate in the study. The study also adhered to the ethical standards of the Australian sports commission.

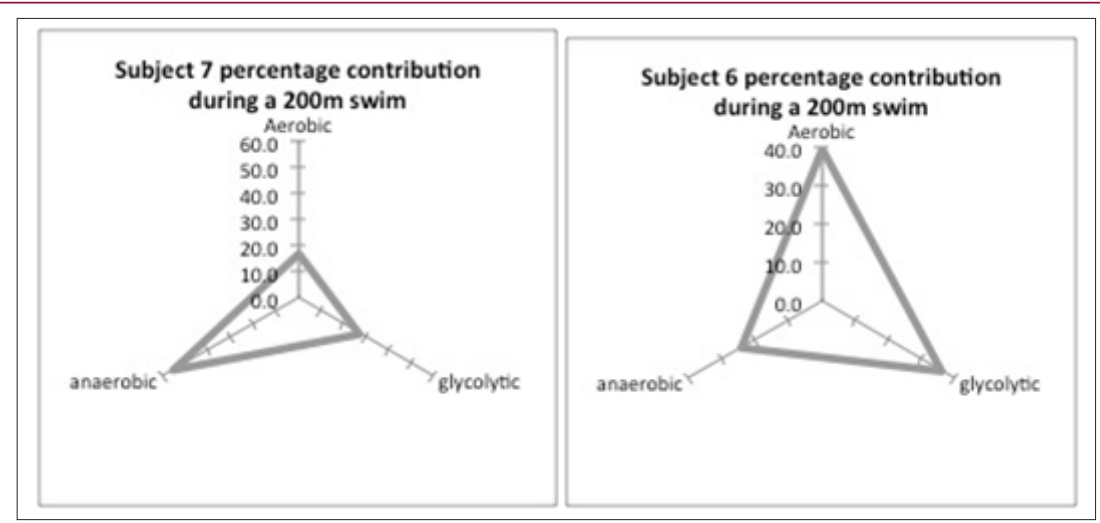

Figure 1: 2 examples of individual responses to a maximal 200m swim.

\section{Experimental Design}

Data was collected using a standardized swimming step test as outlined previously.22 Swimmers were tested at the same time of day on each of 3 occasions (week 0 , week 3 and week 7). Resting blood was taken prior to beginning the step test to give baseline figures. On completion of each swim, the heart rate was immediately recorded using Polar heart rate monitor (Polar Electro OY, Kempele, Finland), and expired air collected for 30 seconds via Douglas bag and measured using a tissout tank, and analysers for Volume, Oxygen concentration, and Carbon Dioxide concentration. The swimming MVO2 was then calculated using backward extrapolation techniques. Blood lactate and glucose were both assessed 1 minute after the completion of the swim using capillary blood drawn from the ear lobe into heprinised capillary tubes, using a YSI 2300 Stat lactate analyser. Additionally, the time for the swim, the stroke count and the stroke rate were all collected for each swim by each swimmer. 


\section{Results}

There were nine parameters measured in each of the 7 swims on each of 3 occasions for each of the 12 swimmers. These results are summarised in Table 1. Swim Time. The percentage change in swim time between tests $1,2 \& 3$ are shown in Figure 2 . Test $1 \& 2$ started at a similar pace $(151.7 \pm 7.3) \mathrm{sec}$ vs $151.32 \pm 4 \pm .23 \mathrm{sec})$ but test 2 finished faster ( $120.98 \pm 3.17$ sec vs $124.48 \pm 7.35 \mathrm{sec}$ ) Test 3 started faster than test $1 \& 2(147 \mathrm{sec} \pm 9.46)$ but finished with a slower time to test $2(121.13 \pm 2.75 \mathrm{sec}$. vs $120.98 \pm 3.17 \mathrm{sec})$ and faster than test 1 . When the mean time of 7 swims was taken, the time of swim were significantly faster between test 1 and test 2 (Mean difference $1.77 \mathrm{sec} \pm 1.25 \mathrm{sec}$; $\mathrm{P}=0.04)$. There was a significant slowing of times between test 2 and test $3(-1.32 \mathrm{sec} \pm 1,78 \mathrm{sec}$; $\mathrm{P}=$ $0.005)$, but there was no significant difference between test 1 and 3 (1.58 sec $\pm 1.75 \mathrm{sec}$; $\mathrm{P}=0.39$ )

Table 1: Average gains and losses between test $1 \& 2,2 \& 3$, and $1 \& 3$ for all parameters measured.

\begin{tabular}{|c|c|c|c|c|c|c|c|c|c|c|}
\hline \multicolumn{11}{|c|}{ Test 1 compared to Test 2} \\
\hline & Time & $\mathrm{HR}$ & $\overline{L a}$ & Glu & $\mathrm{VO2}$ & RER & RPE & SR & SC & S| \\
\hline Mean & 137.85 & 170.14 & 6.53 & 5.73 & 3.21 & 1.19 & 14.86 & 32.47 & 32.57 & 2.39 \\
\hline Standard Deviation & 10.33 & 21.89 & 6.29 & 1.26 & 0.55 & 0.17 & 4.10 & 6.45 & 3.95 & 0.12 \\
\hline overall $\%$ change & $-0.87 \%$ & $3.0 \%$ & $-9.9 \%$ & $-3.8 \%$ & $28.0 \%$ & $-0.1 \%$ & $.5 .7 \%$ & $-2.5 \%$ & $1.0 \%$ & $-3.6 \%$ \\
\hline$p=0.05$ & 0.269 & 0.329 & 0.282 & 0.340 & 0.001 & 0.500 & 0.374 & 0.412 & 0.443 & 0.079 \\
\hline$\%$ change 1 st 4 swims & $3.90 \%$ & $4.9 \%$ & $16.8 \%$ & $2.5 \%$ & $28.5 \%$ & $1.6 \%$ & $-4.3 \%$ & $-1.5 \%$ & $2.5 \%$ & $-2.9 \%$ \\
\hline$\%$ change last 3 swims & $3.60 \%$ & $0.2 \%$ & $.54 .0 \%$ & $-12.0 \%$ & $27.4 \%$ & $-1.7 \%$ & $-5.7 \%$ & $-3.3 \%$ & $-0.9 \%$ & $-4.6 \%$ \\
\hline 1 st 4 swims $p=0.05$ & 0.132 & 0.229 & 0.282 & 0.379 & 0.001 & 0.379 & 0.406 & 0.361 & 0.049 & 0.204 \\
\hline last 3 swims $p=0.05$ & 0.159 & 0.466 & 0.143 & 0.202 & 0.002 & 0.398 & 0.234 & 0.329 & 0.401 & 0.108 \\
\hline Upper confidence limit $\%$ & $0.04 \%$ & $7.09 \%$ & $27.52 \%$ & $4.81 \%$ & $30.84 \%$ & $4.12 \%$ & $-1.34 \%$ & $0.78 \%$ & $3.19 \%$ & $-0.23 \%$ \\
\hline Lower confidence limit $\%$ & $-1.79 \%$ & $-1.17 \%$ & $-47.32 \%$ & $-12.48 \%$ & $25.18 \%$ & $-4.37 \%$ & $-9.96 \%$ & $-5.70 \%$ & $-1.16 \%$ & $-7.06 \%$ \\
\hline \multicolumn{11}{|c|}{ Test 2 compared to Test 3} \\
\hline & Time & $\mathrm{HR}$ & La & Glu & $\mathrm{VO} 2$ & RER & RPE & SR & $\mathrm{SC}$ & SI \\
\hline Mean & 136.71 & 174.86 & 4.94 & 5.49 & 4.45 & 1.19 & 14.14 & 31.70 & 32.86 & 2.30 \\
\hline Standard Deviation & 10.94 & 16.48 & 3.24 & 0.85 & 0.70 & 0.17 & 4.06 & 6.32 & 3.39 & 0.08 \\
\hline overall $\%$ change & $-0.3 \%$ & $-6.9 \%$ & $12.6 \%$ & $2.0 \%$ & $-22.7 \%$ & $1.0 \%$ & $-8.1 \%$ & $0.0 \%$ & $1.8 \%$ & $-1.9 \%$ \\
\hline$p=0.05$ & 0.364 & 0.161 & 0.294 & 0.405 & 0.050 & 0.440 & 0.356 & 0.486 & 0.370 & 0.140 \\
\hline$\%$ change 1 st 4 swims & $2.7 \%$ & $-9.4 \%$ & $-5.3 \%$ & $2.4 \%$ & $.22 .9 \%$ & $-0.2 \%$ & $-12.2 \%$ & $1.4 \%$ & $3.2 \%$ & $-3.3 \%$ \\
\hline$\%$ change last 3 svims & $2.4 \%$ & $-3.3 \%$ & $25.8 \%$ & $1.1 \%$ & $-17.4 \%$ & $2.7 \%$ & $-1.9 \%$ & $-2.1 \%$ & $0.0 \%$ & $-0.1 \%$ \\
\hline 1 st 4 swims $p=0.05$ & 0.192 & 0.082 & 0.418 & 0.369 & 0.066 & 0.485 & 0.292 & 0.361 & 0.015 & 0.122 \\
\hline last 3 swims $p=0.05$ & 0.274 & 0.191 & 0.212 & 0.453 & 0.019 & 0.372 & 0.401 & 0.403 & 0.500 & 0.385 \\
\hline Upper confidence limit $\%$ & $0.84 \%$ & $-2.38 \%$ & $26.50 \%$ & $7.59 \%$ & $-8.77 \%$ & $4.85 \%$ & $-1.70 \%$ & $2.58 \%$ & $3.41 \%$ & $-0.16 \%$ \\
\hline Lower confidence limit $\%$ & $-1.43 \%$ & $-11.45 \%$ & $-1.36 \%$ & $-3.50 \%$ & $-36.59 \%$ & $-2.80 \%$ & $-14.47 \%$ & $-2.64 \%$ & $0.25 \%$ & $3.68 \%$ \\
\hline \multicolumn{11}{|c|}{ Test 1 compared to Test 3} \\
\hline & Time & $\mathrm{HR}$ & $\mathrm{La}$ & Glu & $\mathrm{VO} 2$ & RER & RPE & $\mathrm{SR}$ & $\mathrm{SC}$ & SI \\
\hline Mean & 136.27 & 164.29 & 6.21 & 5.59 & 3.70 & 1.21 & 13.29 & 31.59 & 33.43 & 2.26 \\
\hline Standard Deviation & 10.07 & 21.52 & 5.11 & 0.67 & 0.86 & 0.18 & 4.42 & 5.53 & 2.88 & 0.06 \\
\hline overall $\%$ change & $1.14 \%$ & $3.4 \%$ & $-12.4 \%$ & $1.0 \%$ & $-15.0 \%$ & $-1.1 \%$ & $11.8 \%$ & $2.4 \%$ & $-3.0 \%$ & $5.2 \%$ \\
\hline$p=0.05$ & 0.388 & 0.311 & 0.460 & 0.398 & 0.110 & 0.440 & 0.252 & 0.394 & 0.326 & 0.015 \\
\hline$\%$ change 1 st 4 swims & $-1.20 \%$ & $.4 .0 \%$ & $21.2 \%$ & $4.9 \%$ & $12.1 \%$ & $1.4 \%$ & $-17.1 \%$ & $-0.1 \%$ & $5.6 \%$ & $-6.3 \%$ \\
\hline$\%$ change last 3 swims & $-1.20 \%$ & $-3.1 \%$ & $-14.3 \%$ & $-10.8 \%$ & $14.7 \%$ & $1.0 \%$ & $.7 .7 \%$ & $-5.5 \%$ & $-0.9 \%$ & $-4.7 \%$ \\
\hline 1st 4 swims $p=0.05$ & 0.345 & 0.303 & 0.231 & 0.162 & 0.187 & 0.379 & 0.205 & 0.489 & 0.002 & 0.057 \\
\hline last 3 swims $p=0.05$ & 0.365 & 0.161 & 0.367 & 0.215 & 0.039 & 0.441 & 0.173 & 0.212 & 0.401 & 0.104 \\
\hline Upper confidence limit $\%$ & $2.09 \%$ & $6.05 \%$ & $12.36 \%$ & $7.99 \%$ & $-3.30 \%$ & $1.84 \%$ & $17.03 \%$ & $4.95 \%$ & $0.11 \%$ & $7.74 \%$ \\
\hline Lower confidence limit $\%$ & $0.18 \%$ & $0.74 \%$ & $-37.23 \%$ & $-5.91 \%$ & $-26.64 \%$ & $-4.13 \%$ & $6.58 \%$ & $-0.25 \%$ & $-6.04 \%$ & $2.73 \%$ \\
\hline
\end{tabular}

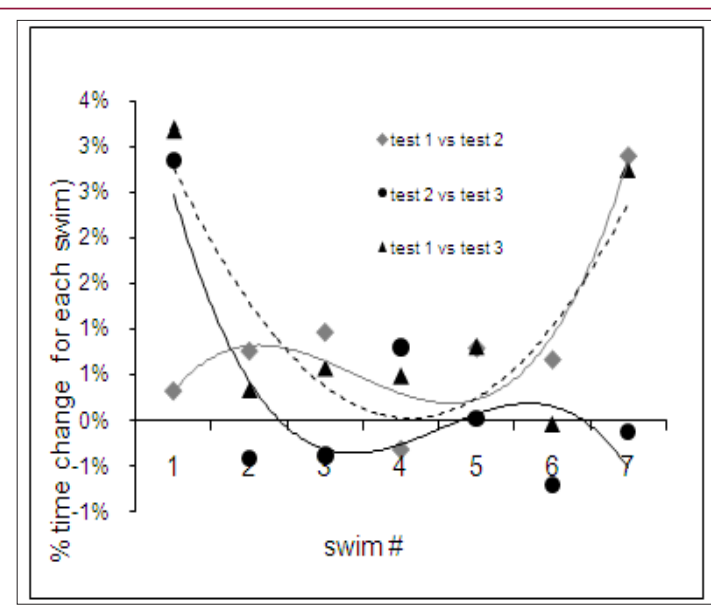

Figure 2: Percentage change in time over 3 swim tests (week $0,3 \& 7$ ).

\section{Lactate, Oxygen Uptake, Heart Rate \& Glucose}

The trend of Heart Rate (HR) Lactate (La) Glucose (Gu) and Oxygen uptake (VO2) are shown in Figure 3. Heart rate showed a $3.24 \%( \pm 4.88 \%)$ overall rise in the 3 weeks between test 1 and test 2 but a $6.30 \%( \pm 4.55 \%)$ reduction in the 3 week period of training between the $2^{\text {nd }}$ and $3^{\text {rd }}$ test. Lactate showed a $1.61 \%( \pm 34.36 \%)$ rise between test 1 and 2 and a $17.22 \%( \pm 19.67 \%)$ rise between test 2 and 3. The large SD in lactate was a function of the large changes seen between individual swim differences (plus and minus values). V02 had the largest changes $39.13 \%( \pm 5.99 \%)$ rise followed by a $17.48( \pm 9.74 \%)$ drop. Glucose had a $3.02 \%( \pm 8.74 \%)$ rise between the first two tests followed by a $2.40 \%( \pm 5.99 \%)$ rise between test 2 and 3. Overall mean changes between week 0 and week 6 were VO2 $14.89 \%( \pm 15.08 \%)$, heart rate $-3.18 \%( \pm 3.43 \%)$ lactate $(14.90 \%$ $( \pm 31.14 \%)$ and glucose $(-0.83 \%( \pm 8.95 \%)$ (Figure 3$)$. 


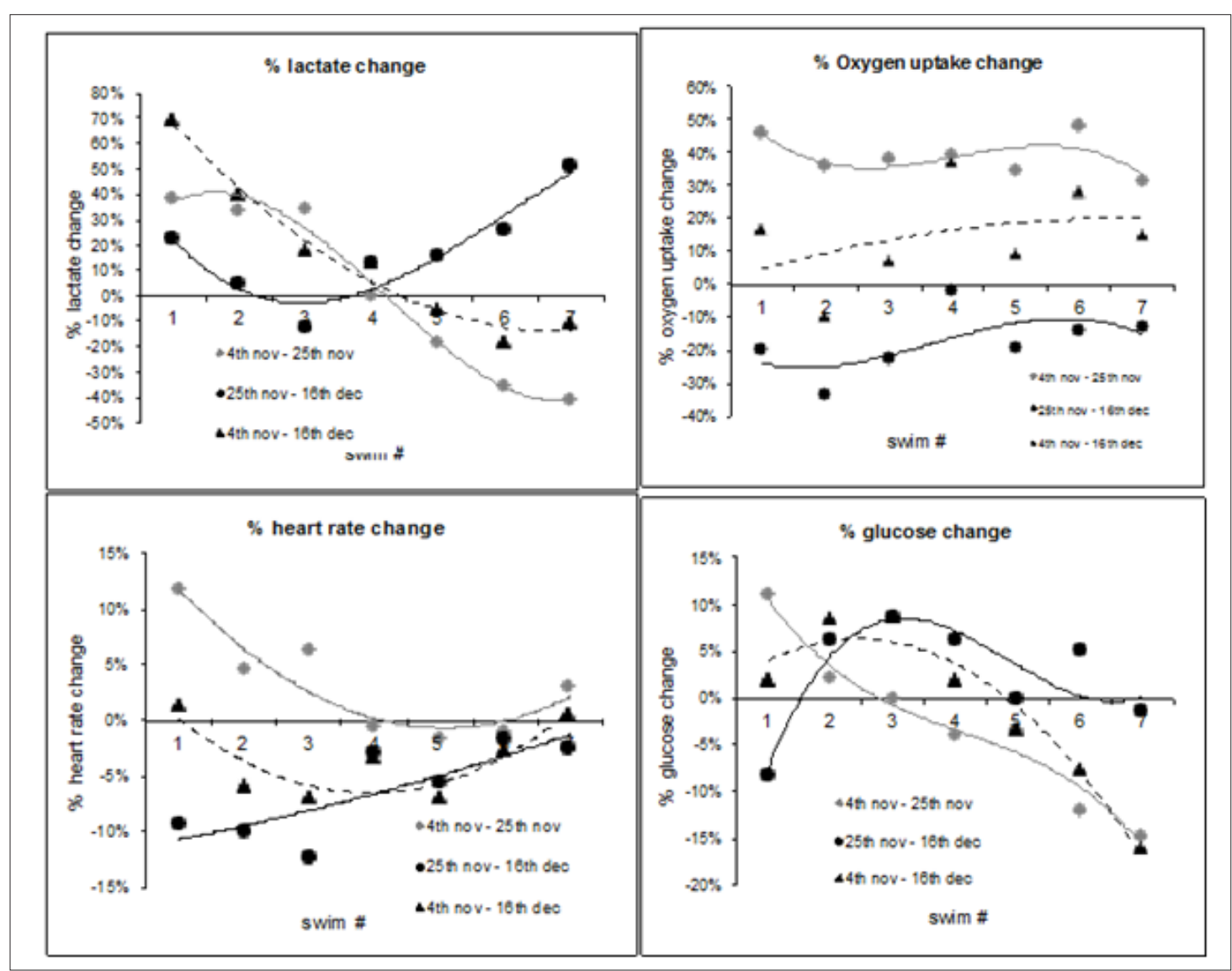

Figure 3: Percentage change between test $1 \& 2$, test $2 \& 3$ and test $1 \& 3$, for VO2 (L/min), Heart rate (bpm), Lactate $(\mathrm{mmol} / \mathrm{l})$ \& glucose $(\mathrm{mmol} / \mathrm{l})$.

For comparative purposes, the results from each test were split in half on a rough identity of "greater aerobic" and "greater anaerobic" contribution to the swim in each half of the test. Table 1 shows the overall differences (as a percentage of change) between each test and also shows the percentage changes in each half of the test for each of the monitored parameters. There were increases in heart rate $(2.7 \% \mathrm{P}<0.001)$, lactate $(-32 \% \mathrm{P}<0.001)$, glucose $(-4.4 \%$ $\mathrm{P}<0.001)$, VO2 $(27.9 \% \mathrm{P}<0.001)$. RER was unchanged $(\mathrm{P}<0.5)$, as was stroke count $(\mathrm{P}<0.05)$ in the first 4 swims. Stroke rate and stroke index were reduced. In the last 3 swims, there was only an increase in VO2 ( $\mathrm{P}=0.002)$, minimal change in heart rate and stroke count, but reductions in lactate, glucose, RER, stroke rate, and stroke index. RPE was equally reduced between test 1 and 2 , for both the first 4 and last 3 swims.

Between test 2 and 3 (weeks 3 to 6 ) the first 4 swims showed reductions in heart rate and VO2 but increases in lactate, glucose, stroke rate and stroke count $(\mathrm{P}<0.02)$. RER remained unchanged. RPE was reduced in the first 4 swims but only slightly reduced in the latter 3 swims. In these swims heart rate was further reduced but only moderately. VO2 was significantly reduced $(\mathrm{P}=0.02)$, while stroke rate was reduced stroke index was relatively unchanged as was stroke count. Lactate, RER and glucose all increased. Overall between week 0 and week 6 , mean changes showed a reduction in heart rate, lactate, glucose, and RPE. VO2 was Increased $13.4 \%$ in the last 3 swims $(P=0.04)$. RPE reduced nearly $12 \%$; there was a reduction in stroke rate and stroke index $(\mathrm{P}=0.02)$ but an increase in stroke count, significantly so in the lower intensity swims ( $\mathrm{P}=$ 0.002). Although there were marked differences in the kilocalories used between test 1 and 2, there was only a significant difference between test 2 and test 3 (Table 2). The energy cost of the step test dropped between test 1 and 2 . By test 3 , there was little difference in the energy cost of test 1 and 3 Table 2.

Table 2: Comparison of kilocalories per minute use in tests 1,2 $\& 3$.

\begin{tabular}{|c|c|c|c|}
\cline { 2 - 4 } \multicolumn{1}{c|}{} & \multicolumn{3}{c|}{ Kcal used per swim } \\
\cline { 2 - 4 } \multicolumn{1}{c|}{} & $\begin{array}{c}\text { Kcal } \\
\text { 4th nov }\end{array}$ & $\begin{array}{c}\text { Kcal } \\
\text { 25th nov }\end{array}$ & $\begin{array}{c}\text { Kcal } \\
16 \text { th dec }\end{array}$ \\
\hline swim 1 & 13.17 & 15.57 & 15.49 \\
\hline swim 2 & 12.25 & 13.70 & 14.59 \\
\hline swim 3 & 13.71 & 15.73 & 15.38 \\
\hline swim 4 & 17.94 & 17.56 & 19.33 \\
\hline swim 5 & 26.76 & 22.83 & 25.22 \\
\hline swim 6 & 38.61 & 26.84 & 32.49 \\
\hline swim 7 & 54.78 & 34.03 & 46.83 \\
\hline sum & 177.22 & 146.25 & 169.33 \\
\hline mean & 25.32 & 20.89 & 24.19 \\
\hline st dev & 16.10 & 7.41 & 11.91 \\
\hline & $\mathrm{t} 1-\mathrm{t} 2$ & $\mathrm{t} 2-\mathrm{t} 3$ & $\mathrm{t} 1-\mathrm{t} 3$ \\
\hline p = & 0.11 & 0.05 & 0.26 \\
\hline steyx & 1.77 & 0.99 & 1.14 \\
\hline
\end{tabular}


Comparison of how the systems of energy energy generation were used (as defined above), are shown in Figure 4 and Table 3. Aerobic contribution grew more than $11.14 \%( \pm 27.40 \%)$ between test 1 and $2(\mathrm{P}=0.05)$ and then dropped between test 2 and 3 by $2.89 \%( \pm 16.91 \%$; $=0.08)$. Overall change between test 1 and 3 was $8.25 \%( \pm 19.74 \%)$. Glycolytic metabolism showed a reduction in contribution of $7.79 \%( \pm 24.37 \%)$ between test 1 and 2 and a further larger reduction in contribution between test 2 and 3 $(12.61 \% \pm 15.26 \%)$ neither of these were significant. The overall change from week 0 to week 6 was $20.40 \%( \pm 10.82 \%)$ that was significant $(\mathrm{P}=0.04)$. Anaerobically, there was a small reduction between test 1 and $2(3.36 \% \pm 16.70 \%)$ followed by a significant gain in anaerobic contribution $(15.51 \% \pm 7.66 \%$; $\mathrm{P}=0.001)$ leading to an overall gain of $12.15 \%( \pm 11.70 \%$; $\mathrm{P}=0.01)$

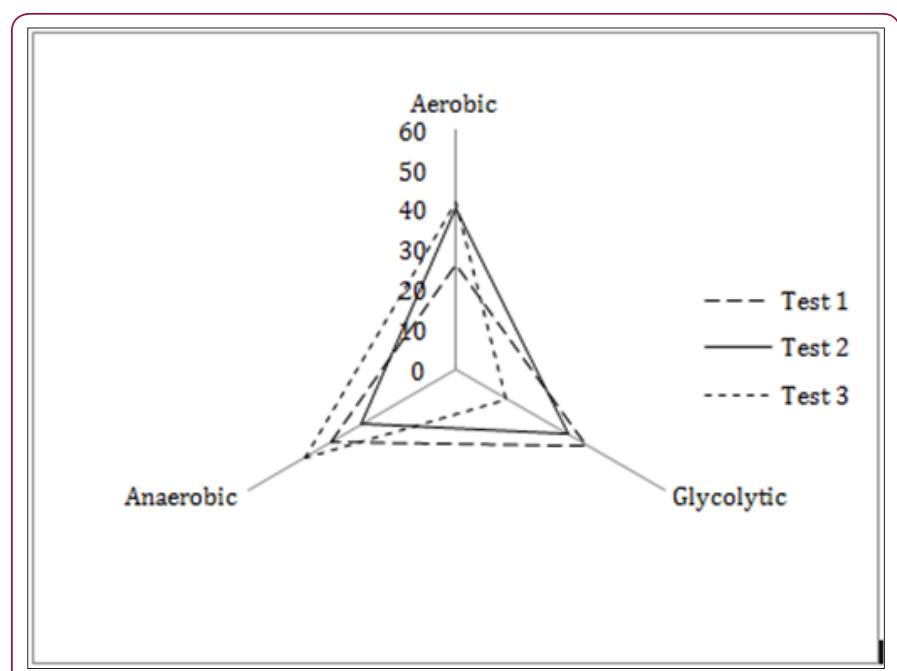

Figure 4: Changes in percentage energy contribution through 3 tests.

Table 3: Percentage contribution of each pathway.

\begin{tabular}{|c|c|c|c|}
\hline & Pathway & Mean & conf \\
\hline \multirow{4}{*}{ Test 1} & Aerobic & $31.25 \%$ & 22.91 \\
\hline & Glycolytic & $34.98 \%$ & 20.37 \\
\hline & Anaerobic & $33.77 \%$ & 12.82 \\
\hline & Aerobic & $42.39 \%$ & 14.14 \\
\hline \multirow[t]{3}{*}{ Test 2} & Glycolytic & $27.20 \%$ & 12.76 \\
\hline & Anaerobic & $30.41 \%$ & 5.52 \\
\hline & Aerobic & $39.50 \%$ & 16.50 \\
\hline \multirow[t]{2}{*}{ Test 3} & Glycolytic & $14.58 \%$ & 9.04 \\
\hline & Anaerobic & $45.92 \%$ & 9.19 \\
\hline
\end{tabular}

\section{Discussion}

This paper presented a new method of exercise intensity analysis that redefined the energy system model 21 to look at the issue of monitoring training. This model splits aerobic function into 2 distinct parts, the purely aerobic (that uses fatty acids and circulating blood sugar supported by liver glycogenolysis) and an aerobic function that is based on a better understanding of the role played by the malate aspartate shuttle (MAS) which we termed aerobic glycolysis. MAS has a far greater role to play in retaining the equilibrium within skeletal muscle that allows higher intensity of aerobic exercise to continue in less aerobically friendly conditions [23]. One of the major observations of this study was that the changes that occurred during the step test could be defined by step, as well as an overall summary of the maximal intensity response. There was marked differences between responses to training at lower intensities than those at higher intensities. We feel that this greatly increases the ability to understand the training load placed on swimmers at any given time during a training session. This is distinctly different to the other variables measured in this and many other studies. Monitoring training load has proved difficult in swimming. Using heart rate, RPE, and distance have not produced effective results.14 The need for individualization and specialization of training with elite swimmers has been discussed previously [24]. By looking back at results and training diaries over 12 years, this group demonstrated that the design of the overload period and the taper periods required specific shaping if increased performance was to be achieved. The ability to achieve this design and monitor its effect while doing it has proven more difficult. Physiological predictors of swimming performance, particularly in adolescents has been shown to be less than reliable (45.8\%) and less so than using stroke index (swim speed $\mathrm{x}$ stroke length).19 The present methodology makes use of the link between lactate \& MAS.8 This allows the transfer of a proton from lactate to the inner mitochondrial membrane. By doing so, both $\mathrm{pH}$ balance can be retained and greater pyruvate can also enter the mitochondria while also regenerating NAD +.25 This produces a total of 4 ATP molecules (net of 6 ATP) by aerobically generated oxidative phosphorylation in skeletal muscle. With the addition of a pyruvate molecule being passed through to the mitochondria a further $5 \mathrm{NADH} / \mathrm{FADH}$ can be created (between $7 \& 10$ ATP). As such, this mechanism would sustain aerobic metabolism significantly, particularly when under aerobic stress. Indeed, the time line that would be produced by this smaller generation of ATP per unit of oxygen would probably sustain activity for approximately 20-30 mins, where $500 \mathrm{~g}$ of glycogen was available in the skeletal muscles. The model is calculated through the inter-relationship of the blood lactate and blood glucose responses to the exercise intensity.21, 26 Understanding how the MAS can control or be overloaded by the prescribed workload also gives us an opportunity to control training stimulus with far greater effect [23].

Although the relationship between submaximal heart rate and MVO2 do not share a good relationship,27 adjustments in heart rate are still viewed as indications of improvements in aerobic capacity and endurance performance,28 although there was a rise in heart rate at submaximal levels in the first 3 weeks with no change at maximal intensities. In the $2^{\text {nd }}$ three weeks there was a noticeable drop in heart rate both at submaximal intensities (6.3\%) and maximal $(8.4 \%)$. It was this secondary response that led to the overall reduction in heart rate $(3.4 \%)$ that is associated with an increase in aerobic capacity.10, 29 The change in heart rate represented approximately $40 \%$ of the change in aerobic capability seen in the model used.

Adaptations at cellular level are generally assumed to be due to adaptations in muscle citrate synthase, PFK, and all the 
other enzymes that mediate an increase in aerobic capacity at mitochondrial and cellular level.30 Such changes are not explained by the smaller changes in only the aerobic metabolism as presented here but will be present in the glycolytic changes observed. The changes seen in blood lactate over the 6 weeks are not singularly representative of the changes seen in the model. This should further help to explain why reliance on lactate per se is less reliable in predicting training outcomes in competition [19-30].

\section{Conclusion}

Understanding training load in training has proved difficult to define in most sports and particularly in swimming. We demonstrated how the use of a new model of metabolic capability may help to explain physiological changes made by the athlete in response to the coaches intended outcome. This model is easy to monitor, reliable and reproducible. As such it gives the coach and sport scientist a much greater insight to be able to identify the likelihood of success in performance. It does this by allowing the changes in metabolism to be tracked toward the event metabolic balance requirement. Not having this balance correctly trained means an athlete will not have the capability of achieving their full performance potential.

\section{Practical Applications}

The tri-phasic methodology is not limited to working with just swimming. It has been used with a range of sports including but not limited to, Rugby, Rowing, Boxing, Cycling, Triathlon and other field based games. It provides a better and easily accessible view of what and how the athlete is being loaded, and offers an insight of how to modify training to achieve optimum energy balance during competition.

\section{References}

1. Pyne DB, Trewin CB, Hopkins WG (2004) Progression and variability of competitive performance of Olympic swimmers. Journal of sports sciences 22(7): 613-620.

2. Anderson M, Hopkins W, Roberts A, Pyne D (2008) Ability of test measures to predict competitive performance in elite swimmers. Journal of Sports Sciences 26(2): 123-130.

3. Mujika I, Chatard JC, Busso T, Geyssant A, Barale F, et al. (1995) Effects of training on performance in competitive swimming. Canadian Journal of Applied Physiology 20(4): 395-406.

4. García Pallarés J, García Fernández M, Sánchez Medina L, Izquierdo M (2010) Performance changes in world-class kayakers following two different training periodization models. European journal of applied physiology 110(1): 99-107.

5. Mäestu J, Jürimäe J, Jürimäe T (2005) Monitoring of performance and training in rowing. Sports medicine 35(7): 597-617.

6. Costa MJ, Bragada JA, Marinho DA, Silva AJ, Barbosa TM (2012) Longitudinal interventions in elite swimming: a systematic review based on energetics, biomechanics, and performance. The Journal of Strength \& Conditioning Research 26(7): 2006-2016.

7. Pyne DB, Lee H, Swanwick KM (2013) Monitoring the lactate threshold in world-ranked swimmers. Medicine \& Science in Sports \& Exercise 33(2): 291-297.

8. Mujika I, Padilla S, Pyne D, Busso T (2004) Physiological changes associated with the pre-event taper in athletes. Sports Medicine 34(13): 891-927.
9. Anderson ME, Hopkins WG, Roberts AD, Pyne DB (2006) Monitoring seasonal and long-term changes in test performance in elite swimmers. European Journal of Sport Science 6(3): 145-154.

10. Wakayoshi K, Yoshida T, Ikuta Y, Mutoh Y, Miyashita M (1993) Adaptations to six months of aerobic swim training. International Journal of Sports Medicine 14(7): 368-372.

11. Toubekis AG, Tsami AP, Smilios IG, Douda HT, Tokmakidis SP (2011) Training-induced changes on blood lactate profile and critical velocity in young swimmers. The Journal of Strength \& Conditioning Research 25(6): 1563-1570.

12. Stewart AM, Hopkins WG (1997) Swimmers' compliance with training prescription. Medicine and science in sports and exercise 29(10): 13891392.

13. Stewart AM, Hopkins WG (2000) Consistency of swimming performance within and between competitions. Medicine and Science in Sports and Exercise 32(5): 997-1001.

14. Wallace LK, Slattery KM, Coutts AJ (2009) The ecological validity and application of the session-RPE method for quantifying training loads in swimming. The Journal of Strength \& Conditioning Research 23(1): 3338.

15. O'Toole ML, Douglas PS, Hiller WD (1998) Use of heart rate monitors by endurance athletes: lessons from triathletes. The Journal of sports medicine and physical fitness 38(3): 181-187.

16. Jeukendrup A, Diemen AV (1998) Heart rate monitoring during training and competition in cyclists. Journal of Sports Sciences 16(1): 91-99.

17. Plews DJ, Laursen PB, Kilding AE, Buchheit M (2012) Heart rate variability in elite triathletes, is variation in variability the key to effective training? A case comparison. European journal of applied physiology 112(11): 3729-3741.

18. Plews DJ, Laursen PB, Stanley J, Kilding AE, Buchheit M (2013) Training adaptation and heart rate variability in elite endurance athletes: opening the door to effective monitoring. Sports medicine 43(9): 773-781.

19. Lätt E, Jürimäe J, Mäestu M, Purge P, Rämson R, etal. (2010) Physiological, biomechanical and anthropometrical predictors of sprint swimming performance in adolescent swimmers. Journal of sports science \& medicine 9(3): 398-404.

20. Spencer MR, Gastin PB (2001) Energy system contribution during 200to $1500-m$ running in highly trained athletes. Medicine \& Science in Sports \& Exercise 33(1): 157-162.

21. Swanwick EK, Matthews MJ (2018) Energy Systems; A New Look At Aerobic Metabolism In Stressful Exercise 1(2): 15-22.

22. Tanner R, Gore C (2012) Physiological Tests for Elite Athletes (2 ${ }^{\text {nd }}$ Edn.); Human Kinetics.

23. Kane DA (2014) Lactate oxidation at the mitochondria: a lactate-malateaspartate shuttle at work. Frontiers in neuroscience pp. 8-366.

24. Hellard P, Avalos M, Hausswirth C, Pyne D, Toussaint JF, et al. (2013) Identifying optimal overload and taper in elite swimmers over time. Journal of sports science \& medicine 12(4): 668-678.

25. Putman CT, Jones NL, Lands LC, Bragg TM, Hollidge Horvat MG, et al. (1995) Skeletal muscle pyruvate dehydrogenase activity during maximal exercise in humans. Am J Physiol 269(3): 458-468.

26. Swanwick EK, Matthews MJ The effects of pre-exercise blood glucose on responses to short duration high intensity exercise. International Journal of Sports and Exercise Medicine 4(1): 1-7.

27. Fox EL, Bartels RL, Billings CE, O’Brien R, Bason R, et al. (1975) Frequency and duration of interval training programs and changes in aerobic power. Journal of Applied Physiology 38(3): 481-484.

28. Skinner JS, Gaskill SE, Rankinen T, Leon AS, Rao DC, et al. (2003) Heart rate versus\% V02max: age, sex, race, initial fitness, and training response--HERITAGE. Medicine and science in sports and exercise 35(11): 1908-1913. 
29. Wisløff U, Støylen A, Loennechen JP, Bruvold M, Rognmo Ø, et al. (2007) Superior cardiovascular effect of aerobic interval training versus moderate continuous training in heart failure patients. Circulation 115(24): 3086-3094.

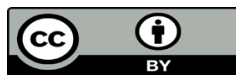

This work is licensed under Creative Commons Attribution 4.0 License

Submission Link: https://biomedres.us/submit-manuscript.php
30. Vigelsø A, Andersen NB, Dela F (2014) The relationship between skeletal muscle mitochondrial citrate synthase activity and whole body oxygen uptake adaptations in response to exercise training. International journal of physiology, pathophysiology and pharmacology 6(2): 84-101.

Assets of Publishing with us
- Global archiving of articles
RESEARCHES

